\title{
Axillary temperature measurements based on smart wearable thermometers in South Korean children: comparison with tympanic temperature measurements
}

\author{
Younglee Choi ${ }^{1}$, Hye Young Ahn ${ }^{2}$ \\ ${ }^{1}$ Lecturer, College of Nursing, Eulji University, Uijeongbu; ${ }^{2}$ Professor, College of Nursing, Eulji University, Uijeongbu, Korea
}

Purpose: This study explored the validity of a new type of thermometer and parent satisfaction with the new device. This 24-hour continuous monitoring smart wearable wireless thermometer (TempTraq $\left.{ }^{\circledR}\right)$ uses a very small semiconductor sensor with a thin patch-like shape. Methods: We obtained 397 sets of TempTraq ${ }^{\circledR}$ axillary temperatures and tympanic temperatures from 44 pediatric patients. Agreement between the axillary and tympanic measurements, as well as the validity of the TempTraq ${ }^{\circledR}$ axillary temperatures, were evaluated. Satisfaction surveys were completed by 41 caregivers after the measurements. Results: The TempTraq ${ }^{\circledR}$ axillary temperatures demonstrated a strong positive correlation with the tympanic temperatures. The Bland-Altman plot and analysis of TempTraq ${ }^{\circledR}$ axillary temperatures and tympanic temperatures showed that the mean difference was $+0.45{ }^{\circ} \mathrm{C}$, the $95 \%$ limits of agreement were -0.57 to $+1.46{ }^{\circ} \mathrm{C}$. Based on a tympanic temperature of $38{ }^{\circ} \mathrm{C}$, the results of validity of fever detection were sensitivity 0.85 and specificity 0.86 . Satisfaction scores for TempTraq ${ }^{\circledR}$ temperature measurement were all $>4$ points (satisfactory). Conclusion: TempTraq ${ }^{\circledR}$ smart axillary temperature measurement is an appropriate method for measuring children's temperatures since it was highly correlated to tympanic temperatures, had a reliable level of sensitivity and specificity, and could be used safely and conveniently.

Key words:: Body temperatures; Thermometers; Wearable electronic devices; Child

\author{
Corresponding author \\ Hye Young Ahn \\ College of Nursing, Eulji University,712 \\ Dongil-ro, Uijeongbu 11759, Korea \\ TEL: +82-31-951-3813 \\ FAX: +82-31-951-3916 \\ E-MAIL: ahanaya@eulji.ac.kr
}

This article was adapted from a thesis by Younglee Choi in partial fulfillment of the requirements for the master's degree at Eulji University.

Received Oct 4, 2021

Revised Nov 1, 2021

Accepted Nov 11, 2021

This is an Open Access article distributed under the terms of the Creative Commons Attribution NonCommercial License (http://creativecommons.org/licenses/by-nc/4.0/) which permits unrestricted noncommercial use, distribution, and reproduction in any medium, provided the original work is properly cited.

\section{INTRODUCTION}

Physiological indicators of body include temperature, blood pressure, pulse, electrocardiogram, and oxygen saturation. Among these, temperature is a sensitive and reliable indicator that can be used to evaluate patients' conditions, identify problems, and reflects the presence and progress of disease. Temperature is important information for the diagnosis and treatment of disease and for nursing care [1].

The immature immune systems of infants and toddlers make them vulnerable to frequent viral and bacterial infections that can cause high fevers [2]. It is particularly important to accurately measure the temperature of newborn babies. The heat transfer rate is high because the surface area to body mass ratio is three times larger than that of adults, and the skin, subcutaneous fat layer, and muscular layer are thin [3].

Various types of thermometers are used depending on the part of the body used to measure temperature. In the recent past, body temperature was primarily measured in the oral cavity and the axilla with a glass mercury thermometer or an electronic thermometer. However, body temperature is currently measured in the tympanic membrane or forehead with an infrared thermometer, which has a short reading time [4].

In recent years, wearable devices such as smart watches, glasses, and bands have been developed for the purpose of monitoring fitness and health. Wearable thermometers have also been developed and marketed, such as the TempTraq ${ }^{\circledR}$ (Model TT-100, Blue Spark Technologies, Westlake, OH, USA), a 24-hour continuous monitoring smart wearable wireless thermometer, introduced in the United States in May 2015. The TempTraq ${ }^{\circledR}$ wearable wireless thermometer transmits body temperature information to a portable electronic device via wireless Bluetooth for 24 hours when attached to the body and, if the temperature goes higher than the set temperature, it sounds an alarm. When temperature is measured periodically, as with the existing temperature measurement 
methods, fever may not be detected early enough and increasing/decreasing temperature trends cannot be clearly identified. Making physical contact to measure temperature with a regular thermometer may also disturb children who need rest to recover. A wearable thermometer enables remote monitoring for up to 24 hours and provides a real-time alarm system to detect fever so that timely interventions can be provided. In addition, using a wearable thermometer can minimize direct contact between the caregiver and the child with an infectious disease, helping to prevent the disease from spreading [5].

There are various studies on body temperature measurement, including studies to identify non-invasive measurements of temperature that best reflect the core body temperature [6,7], studies on the accuracy of each type of thermometer [8-10], and systematic reviews of the accuracy of non-core thermometer devices $[11,12]$. However, there are a limited number of studies on wearable thermometers [13-15]. Therefore, it was necessary to study the validity and efficacy of a new type of thermometer-the 24-hour continuous monitoring smart wearable wireless thermometer (TempTraq ${ }^{\circledR}$ ).

The purpose of this study was to compare the accuracy of 24-hour continuous monitoring axillary temperature measurements (using a smart wearable, wireless thermometer) with tympanic temperature measurements in children with elevated body temperature and to review its clinical usefulness through a parental satisfaction survey.

\section{METHODS}

Ethics statement: This study was approved by the institutional review board of Eulji University Hospital (EMC 2015-10-015-003). Informed consent was obtained from the participants.

\section{Study Design and Data Collection}

This study is a method-comparison study; it aimed to explore the validity and parents' satisfaction with a new type of thermometer (TempTraq ${ }^{\circledR}$ ) that continuously monitors temperature wirelessly for 24 hours compared to an infrared thermometer that measures tympanic temperature.

\section{Setting and Samples}

Participants included 44 feverish children under 12 years old admitted to the Eulji University Hospital pediatric ward in Daejeon. The participant inclusion criteria were as follows: 1) children under 12 years old whose parents or guardians voluntarily agreed to participate in the study; 2) had fever over $38^{\circ} \mathrm{C}$ within the past 24 hours. Exclusion criteria were: 1 ) having ear infections; 2) having skin problems; and 3) being allergies, especially to adhesive bandages, food, or medicine. The sample size was conveniently determined based on the nature of a comparative study between two measurements.

\section{Ethical Considerations}

This study was approved by the Institutional Review Board (EMC 2015-10-015-003) and the Pediatric Department of Eulji University Hospital in Daejeon. At the time of data collection, guardians and participating children received explanations regarding the study's purpose, method, and participation withdrawal options, and informed consent was obtained. Participants were assured that the collected data would be used only for research purposes. Serial numbers were given to the data after removing personal identifiers to ensure personal information protection.

\section{Data Collection and Procedure}

Axillary temperature was measured by TempTraq ${ }^{\circledR}($ Model TT-100, Blue Spark Technologies, Westlake, OH, USA), a 24-hour continuous monitoring smart wearable, wireless thermometer. A thin, soft, breathable electronic patch with an embedded temperature sensor detects the skin temperature and wirelessly transmits it to a portable electronic device via Bluetooth communication. Its accuracy has been tested to the ASTM E1112-00 Standard Specification for Electronic Thermometer [16]. TempTraq ${ }^{\circledR}$ was attached to the center of the child's axilla after the TempTraq ${ }^{\circledR}$ application was installed on a portable electronic device. Real-time temperature information and temperature graphs were then displayed on the handheld electronic device via Bluetooth wireless communication for 24 hours (Figure 1) and the recorded data were exported via e-mail in the form of an Excel file. Tympanic temperature was measured by one researcher using a designated infrared thermometer (Thermo Scan IRT 6520, Braun, Marlborough, MA, USA). Participants' ears were pulled gently to position the thermometer probe to the tympanic membrane for accurate measurements. Measurements were made three times each on the left and right sides, and the average value was used.

After the informed written consent was obtained, the Temp $\operatorname{Traq}^{\circledR}$ smart thermometer was attached to the participant's axilla. Once TempTraq ${ }^{\circledR}$ was activated, the participant's axillary temperature could be monitored via a designated tablet device for 24 hours. The tympanic temperature was measured in the same child every 4 hours while the 24-hour axillary temperature was being monitored. The researcher checked and recorded the TempTraq ${ }^{\circledR}$ axillary temperature while the tym- 
panic temperature was being measured.

Satisfaction surveys were conducted after the 24-hour temperature measurement using the Satisfaction Measurement Tool designed by the authors. The validity of the tool was verified by two nursing professors. As an assessment of the reliability of the tool, Cronbach's $\alpha$ was measured at .88 .

\section{Data Analysis}

The data collected in this study were analyzed using SPSS Statistics 22.0 (IBM Corp., Armonk, NY, USA). The general characteristics of the participants, the satisfaction scores, and the body temperatures were analyzed by frequency, percentage, average, and standard deviation. The Pearson's correlation coefficient was used to evaluate the relationship of the two different measurements, and the paired t-test was used to compare the difference between tympanic and TempTraq ${ }^{\circledR}$ axillary temperature. To analyze the agreement between tympanic and TempTraq ${ }^{\circledR}$ axillary measurements, a Bland-Altman plot (MedCalc version 16.4.1; MedCalc Software, Ostend, Belgium) was used. The sensitivity, specificity, positive predictive value, and negative predictive value of the TempTraq ${ }^{\circledR}$ axillary temperature were calculated against a tympanic temperature of $38.0{ }^{\circ} \mathrm{C}$.

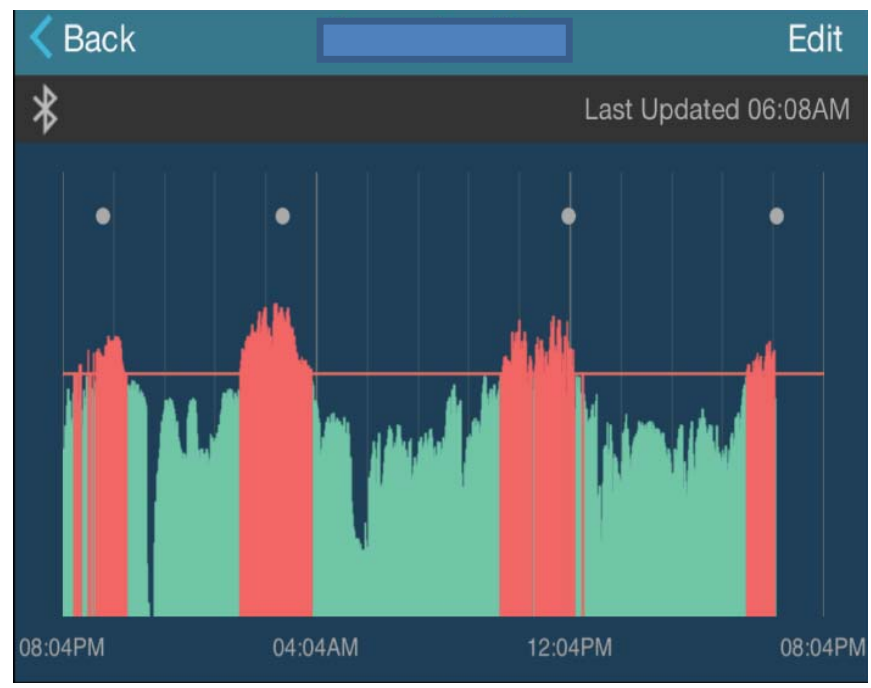

Figure 1. Axillary temperature graph of subject 1 measured by the TempTraq $^{\circledR}$ thermometer.

\section{RESULTS}

\section{General Characteristics of the Participants}

The final participants included 44 children ( 27 boys and 17 girls), ranging in age from $0-11$ years, with an average age of $3.4 \pm 2.9$ years. There were 3 infants $(6.8 \%$, less than 1 year old), 21 toddlers ( $47.7 \%, 1-2$ years old), 12 preschoolers $(27.3 \%, 3-5$ years old), and 8 schoolers (18.2\%, 6-11 years old). The participants were diagnosed with pneumonia $(n=18 ; 40.9 \%)$, acute pharyngotonsillitis $(n=7 ; 15.9 \%)$, acute gastroenteritis $(n=6$; $13.6 \%)$, influenza $(n=4 ; 9.1 \%)$, bronchitis $(n=3 ; 6.8 \%)$, and other diseases $(n=6 ; 13.7 \%)$. Fevers above $38^{\circ} \mathrm{C}$ were seen in 34 participants $(77.0 \%)$ during the 24-hour temperature measurements.

Among the 41 parents or guardians who responded to the survey, 21 (51.2\%) were full-time homemakers, while others were employed in jobs such as office workers and professional workers or were self-employed. The methods that respondents reported using to take a temperature in their household were a tympanic thermometer $(n=34,82.9 \%)$, electronic thermometer $(n=5,12.3 \%)$, non-contact infrared thermometer $(n=1,2.4 \%)$, and touch (feeling the child's skin with their hands) ( $n=1,2.4 \%)$.

\section{Correlation between Tympanic Temperature and TempTraq $^{\circledR}$ Axillary Temperature}

A total of 397 pairs of tympanic temperatures and real-time TempTraq $^{\circledR}$ axillary temperatures were obtained from 44 subjects. The mean tympanic temperature was $37.56 \pm 0.79{ }^{\circ} \mathrm{C}$ and the mean TempTraq ${ }^{\circledR}$ axillary temperature was $37.12 \pm$ $0.93^{\circ} \mathrm{C}$ (Table 1$)$. The TempTraq ${ }^{\circledR}$ axillary temperature demonstrated a strong positive correlation with the tympanic temperature $(\mathrm{r}=.83, p<.001)$ (Figure $2-\mathrm{A})$.

\section{Paired t-test of Tympanic Temperature and TempTraq ${ }^{\circledR}$ Axillary Temperature}

As shown in Table 1, the paired t-test was used to compare the difference between tympanic and TempTraq ${ }^{\circledR}$ axillary temperature, resulting in a statistically significant difference

Table 1. Paired t-test of Tympanic Temperature and TempTraq ${ }^{\circledR}$ Axillary Temperature $(N=397)$

\begin{tabular}{|c|c|c|c|c|}
\hline $\begin{array}{l}\text { Tympanic } \\
\text { temperature }\end{array}$ & $\begin{array}{c}\text { TempTraq }{ }^{\circledR} \text { axillary } \\
\text { temperature }\end{array}$ & $\begin{array}{l}\text { Tympanic temperature } \\
\text { - axillary temperature }\end{array}$ & $\mathrm{t}$ & $p$ \\
\hline$M \pm S D$ & $\mathrm{M} \pm \mathrm{SD}$ & $\mathrm{M} \pm S D$ & & \\
\hline $37.56 \pm 0.79$ & $37.12 \pm 0.93$ & $0.45 \pm 0.52$ & 17.22 & $<.001$ \\
\hline
\end{tabular}


$(\mathrm{t}=17.22, p<.001)$

\section{Agreement between Tympanic Temperature and TempTraq ${ }^{\circledR}$ Axillary Temperature}

The agreement between TempTraq ${ }^{\circledR}$ axillary temperatures and tympanic temperatures was evaluated with a BlandAltman plot. The mean difference was $0.45^{\circ} \mathrm{C}(\mathrm{SD}=0.52)$, the $95 \%$ limits of agreement were -0.57 to $+1.46^{\circ} \mathrm{C}$ (Figure 2-B).

\section{Diagnostic Validity of TempTraq ${ }^{\circledR}$ Axillary Tempera- ture for Fever}

We evaluated the diagnostic validity of the axillary temperature values measured with the TempTraq ${ }^{\circledR}$ thermometer by comparing them with the tympanic temperature measurement data. A tympanic temperature of $38{ }^{\circ} \mathrm{C}$ or above was classified as fever, and 110 out of 397 measurements belonged in this category. For TempTraq ${ }^{\circledR}$ axillary temperatures, $37.5{ }^{\circ} \mathrm{C}$ or above was classified as fever, based on the statistical difference between tympanic and TempTraq ${ }^{\circledR}$ axillary temperatures shown in Table 1. Applying this criterion, 134 out of 397 measurements were classified as fever. The results of the val- idity test were as follows: sensitivity $=0.85$, specificity $=0.86$, positive predictive value $=0.69$, and negative predictive value $=0.93$ (Table 2).

\section{Satisfaction Measurements}

Forty-one parents or guardians completed the Satisfaction Measurement Tool, using a 5-point Likert scale ranging from 1 (very dissatisfied) to 5 (very satisfied). A higher score indicated greater satisfaction with the thermometer. Table 3 lists the items in order of highest satisfaction score and the parent or guardian's self-described reasons for satisfaction or dissatisfaction with the TempTraq ${ }^{\circledR}$ thermometer. The items with high satisfaction scores were "continuous monitoring" (4.5 \pm $0.6)$, "convenience of high fever alarm" (4.5 \pm 0.7$)$, "auto-recording" (4.4 \pm 0.7$)$, and "measuring without disturbing the parent's sleep" ( $4.4 \pm 0.7)$. The item with the lowest score was "easy to measure" (4.2 \pm 0.9$)$ (Table 3).

"Easy to measure" (4.4 \pm 0.6$)$ had the highest satisfaction score for temperature measurements using the tympanic thermometer. "Quick measurement in less than 5 seconds" $(4.2 \pm 0.8)$ and "easy to purchase" (4.2 \pm 0.8$)$ ranked equally (Table 3).
(A)

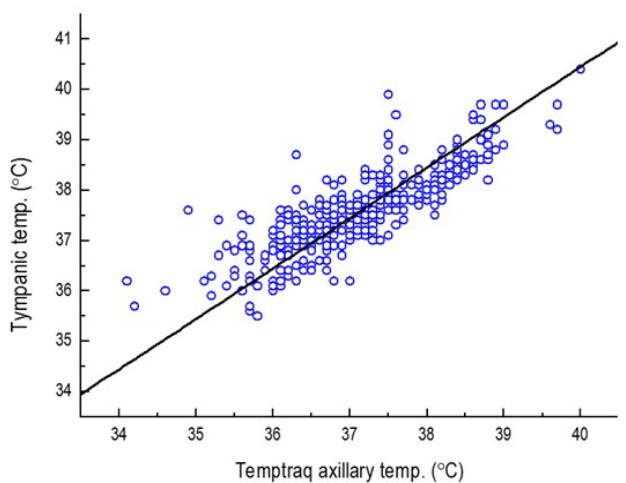

(B)

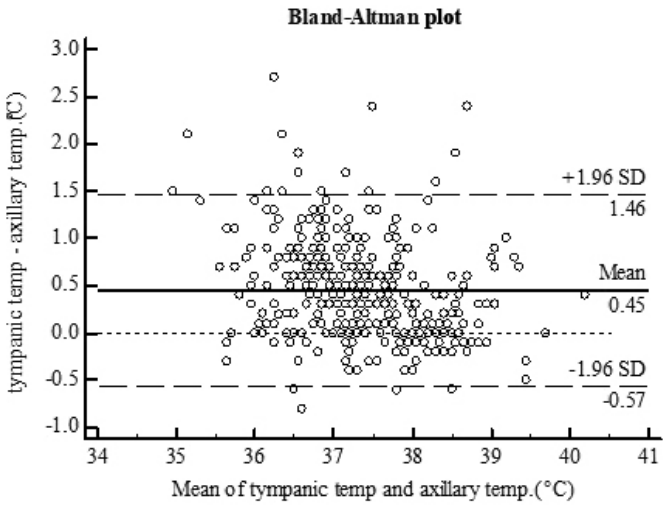

Figure 2. Correlation and agreement between tympanic temperature and TempTraq ${ }^{\circledR}$ axillary temperature.

(A) Correlation $(r=.83, p<.001)$. (B) Agreement. temp, temperature.

Table 2. Diagnostic Validity of TempTraq $^{\circledR}$ Axillary Temperature for Fever $(N=397)$

\begin{tabular}{cccc}
\hline \multirow{2}{*}{$\begin{array}{c}\text { TempTraq } \\
\text { axillary temperature }\end{array}$} & \multicolumn{2}{c}{ Tympanic temperature } & Total \\
\cline { 2 - 3 }$\geq 37.5^{\circ} \mathrm{C}$ & $938^{\circ} \mathrm{C}$ & $<38{ }^{\circ} \mathrm{C}$ & 134 \\
$<37.5^{\circ} \mathrm{C}$ & 17 & 41 & 263 \\
Total & 110 & 287 & 397 \\
\multicolumn{2}{r}{ Sensitivity $=0.85$; Specificity $=0.86$; Positive predictive value $=0.69$; Negative predictive value $=0.93$} \\
\hline
\end{tabular}




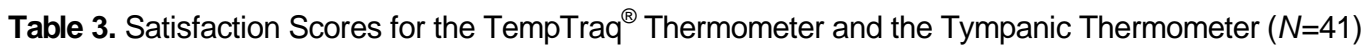

\begin{tabular}{|c|c|c|c|c|}
\hline Ranking & Characteristics of TempTraq $^{\circledR}$ & $\mathrm{M} \pm \mathrm{SD}$ & Characteristics of tympanic thermometer & $\mathrm{M} \pm \mathrm{SD}$ \\
\hline 1 & Continuous monitoring & $4.5 \pm 0.6$ & Easy to measure & $4.4 \pm 0.6$ \\
\hline 2 & Convenience of high fever alarm & $4.5 \pm 0.7$ & Quick measurement in less than 5 seconds & $4.2 \pm 0.8$ \\
\hline 3 & Auto-recording & $4.4 \pm 0.7$ & Easy to purchase & $4.2 \pm 0.8$ \\
\hline 4 & Measuring without disturbing the parent's sleep & $4.4 \pm 0.7$ & More accurate than axillary temperature & $3.9 \pm 0.8$ \\
\hline 5 & Continuous measuring while child is sleeping & $4.4 \pm 0.7$ & & \\
\hline 6 & Autonomic measurement & $4.3 \pm 0.8$ & & \\
\hline 7 & Easy to measure & $4.2 \pm 0.9$ & & \\
\hline
\end{tabular}

Parent/caregiver comments from the satisfaction survey

\begin{abstract}
"A smart thermometer is more hygienic than a tympanic thermometer, my child didn't complain about wearing it and it measures the temperature regularly and automatically, so I highly recommend the smart thermometer to others."

"Since I had to check whether my child is feverish every hour, it was good to find out the temperature right away and it was even better to see how many times and when a fever has gone up."

"I was worried about my child's temperature for 24 hours because she was hospitalized for febrile seizure. It was really convenient, especially when I was nursing in the bed at night, when the temperature was showing on the tablet all the time."

“I compared the TempTraq ${ }^{\circledR}$ temperature with my tympanic thermometer frequently to make sure whether it was correct or not. It was reliable and convenient to show a similar temperature. I was worried because my children were always feverish at night when they were sick. But I'd feel relief if a wearable smart thermometer measures their temperature at night for me."
\end{abstract}

Based on a 5-point scale ranging from 1 (very dissatisfied) and 5 (very satisfied).

\section{DISCUSSION}

The difference between tympanic temperatures and Temp Traq $^{\circledR}$ axillary temperatures $\left(0.45 \pm 0.52^{\circ} \mathrm{C}\right)$ in this study is consistent with previous studies comparing the difference between tympanic and axillary temperatures, in which the tympanic temperatures were 0.2 to $0.8^{\circ} \mathrm{C}$ higher than the axillary temperatures $[11,17,18]$.

The correlation $(\mathrm{r}=.83, p<.001)$ of the tympanic and TempTraq ${ }^{\circledR}$ axillary temperatures was higher than the correlation coefficient of previous studies that examined the correlation between tympanic and axillary temperatures $[7,9,19]$.

The Bland-Altman plots of agreement between the two temperature measurements showed that the data were evenly scattered around the mean difference $\left(0.45^{\circ} \mathrm{C}\right)$. The results of a backtrack analysis of measurements outside the confidence interval were as follows; at the time of the temperature reading, moving or sleeping with the child's arm away from the body; sweating; incorrect thermometer's position; sleeping in an oxygen tent with lower temperature than the outside. If the child was in a caregiver's arms, the TempTraq ${ }^{\circledR}$ axillary temperature tended to be higher than the tympanic temperature.

In this study, the sensitivity of TempTraq ${ }^{\circledR}$ axillary temperature to tympanic temperature was 0.85 and the specificity was 0.86 . In a meta-analysis of the diagnostic accuracy of temperature measurements in children [20], the sensitivity of axil- lary temperatures was 0.00 to 0.86 and the specificity was 0.31 to 1.00 , indicating that the TempTraq ${ }^{\circledR}$ axillary temperature measurements are a valid method for use in children.

Satisfaction with temperature measurements using the TempTraq $^{\circledR}$ was above 4 points (satisfactory). Satisfaction levels for caregivers whose child had experienced febrile seizures, who had difficulty getting up at night, and who experienced the benefits of continuous monitoring were particularly high. Parents whose children had experienced febrile seizures tended to be especially anxious when their children felt sick $[6,21,22]$, and tended to use excessive amounts of antipyretics [23]. The continuous monitoring characteristics of the TempTraq $^{\circledR}$ may be helpful in relieving the anxiety of these parents who are particularly sensitive to temperature. In addition, when monitoring the temperature of a patient who is susceptible to infection, it is possible to quickly identify changes in body temperature and provide a quick response by medical staff [14].

The reasons given by parents or guardians for satisfaction with the TempTraq ${ }^{\circledR}$ thermometer were summarized as convenience, automatic temperature measurement, continuous temperature monitoring, fewer worries, quick response to real-time checks, and minor sleep disturbance. When using the TempTraq $^{\circledR}$ thermometer, caregivers could constantly see real-time changes in temperature, so they felt less anxious, did not have to wake up at night to check the child's temperature, 
and were able to intervene immediately, as soon as a fever started. These advantages may help alleviate some of the parenting stresses experienced while taking care of a sick child.

During the data collection, we found external factors that may influence the temperature of the TempTraq ${ }^{\circledR}$ thermometer. Posture, clothing, sweating, and attachment site tend to affect the temperature. These external factors, except for the attachment site, are not mentioned in the TempTraq ${ }^{\circledR}$ manual, which suggests a need to supplement the manual with this information. It is not easy to fully control these factors, in particular with infants and children, but caregivers should be aware of these limitations and try at least to minimize them. In this study, the clothing condition was controlled because all participants were patients in the same hospital, and utmost care was taken to correctly place the sensors and control the initial posture of patients. Nevertheless, the normal variations (ex., sweating and position changes) over the full course of the measurement span could not be actively controlled, which may be regarded as a limitation of this study. Another limitation was not comparing temperatures according to differences in thermoregulation, due to the lack of neonatal participants who have non-shivering thermogenesis. Further research including neonates is recommended.

In contrast to current temperature measuring methods, the TempTraq ${ }^{\circledR}$ wearable thermometer can remotely and continuously monitor temperature for 24 hours with one attachment without disturbing pediatric patients who need sufficient sleep and rest. From a nursing perspective, this continuous real-time monitoring and alarm system provides the advantage of early detection and intervention for rising temperatures. However, using an adhesive patch-type thermometer such as TempTraq ${ }^{\circledR}$ would be limited for children who have vulnerable skin conditions. Therefore, it is necessary to obtain skin allergy histories before applying, avoid using for more than a specified period, and assess adverse skin reactions around the applied area.

The ideal thermometer should be able to measure body temperature accurately, be easily measurable in a short time, be safe, and be well tolerated by the patient [24]. The experimental results showed that the TempTraq ${ }^{\circledR}$ smart axillary temperature measurements constitute an appropriate method since they are highly correlated to tympanic temperatures, have a reliable level of sensitivity and specificity, and can be used safely and conveniently. In addition, the TempTraq ${ }^{\circledR}$ smart thermometer provides the useful functions of continuous monitoring, auto-recording, and managing the temperature by using smart information technology (IT) equipment and wireless communication. Continuous monitoring makes it possible to identify the pattern of temperature changes (i.e., rises and falls) that conventional thermometers cannot provide. When the alert temperature has been reached, Temp $\operatorname{Traq}^{\circledR}$ notifies the smart device, enabling the child to receive care and treatment in a timely manner. Moreover, the temperature can be checked without disturbing the sleep of children and can help reduce the anxiety of caregivers. Caregivers reported definite satisfaction with these additional functions. However, there were some disadvantages. Differences in posture and the types of clothing worn may influence the external temperature. Furthermore, it was noticed that the communication distance between the child and the portable electronic monitoring device created some temporary errors in monitoring.

The temperature data stored in the smart device may also be stored on the main server of a hospital, with patient and guardian consent, along with the progress of an illness. For this to take place, it is crucial that medical institutions, network system providers, medical device manufacturers, and public institutions related to medical information collaborate organically to provide a solid security system for collected personal medical information [25]. As patient advocates, nursing providers need to be aware of these personal information protection procedures and explain them to their patients. These data are expected to play an important role in new conceptual health services based on 'big data', providing important data linking temperature patterns and disease progression [26]. These new features can benefit patients, caregivers, nurses, and healthcare providers and are good examples of how healthcare services and new technologies can be developed through collaboration. If a wearable health monitoring device such as the TempTraq ${ }^{\circledR}$ can improve the limitations of current technical monitoring devices and lower manufacturing costs, such tools will advance the measurement of important physiological indicators for diagnosis, treatment, and nursing care.

\section{CONCLUSION}

While the healthcare environment is rapidly changing with the utilization of smart electronic technologies, nurses need to embrace these new innovations and utilize them for the full benefit of patients. Some technologies may indeed help improve the quality of patient care, while others may not. Nurses must be involved in evaluating these technologies to determine which can be applied safely in the actual clinical environment and work well for both patients and providers.

Based on the results of this study, the TempTraq ${ }^{\circledR}$ smart axillary temperature measurement device is an appropriate method to measure the body temperature of children who need continuous temperature monitoring since it has high parental satisfaction, is highly correlated to tympanic temperature, and has a reliable level of sensitivity and specificity. The new features of the TempTraq ${ }^{\circledR}$, such as continuous monitor- 
ing, auto-recording, managing the temperature by using smart IT equipment, can benefit patients, caregivers, nurses, and healthcare providers by detecting and managing temperature rise early.

\section{ORCID}

Younglee Choi

Hye Young Ahn

https://orcid.org/0000-0003-4101-7004

https://orcid.org/0000-0002-5353-671X

\section{Authors' contribution}

Conceptualization: all authors; Data collection, Formal analysis: Younglee Choi; Writing-original draft: Younglee Choi; Writing-review and editing: Hye Young Ahn; Final approval of published version: all authors.

\section{Conflict of interest}

No existing or potential conflict of interest relevant to this article was reported.

\section{Funding}

None.

\section{Data availability}

Please contact the corresponding author for data availability.

\section{Acknowledgements}

None.

\section{REFERENCES}

1. Sohng KA, Park HS, Hong YH, Lee KY, Jeong SK, Cho BH, et al. Fundamentals of nursing. Paju: Soomoonsa; 2019. p. 222-224.

2. Jeong YS, Kim JS. Fever and fever management in children: a literature review. Child Health Nursing Research. 2010;16(1):30-40. https://doi.org/10.4094/jkachn.2010.16.1.30

3. Ladewig PW. Essentials of maternal newborn nursing. 3rd ed. Boston, MA: Addison-Wesley; 1994. p. 459-463.

4. Teller J, Ragazzi M, Simonetti GD, Lava SA. Accuracy of tympanic and forehead thermometers in private paediatric practice. Acta Paediatrica. 2014;103(2):e80-e83. https://doi.org/10.1111/apa.12464

5. Seshadri DR, Davies EV, Harlow ER, Hsu JJ, Knighton SC, Walker TA, et al. Wearable sensors for COVID-19: a call to action to harness our digital infrastructure for remote patient monitoring and virtual assessments. Frontiers in Digital Health. 2020;2(8):1-11. https://doi.org/10.3389/fdgth.2020.00008

6. Furlong D, Carroll DL, Finn C, Gay D, Gryglik C, Donahue V. Comparison of temporal to pulmonary artery temperature in febrile patients. Dimensions of Critical Care Nursing. 2015;34(1):47-52. https://doi.org/10.1097/DCC.0000000000000090

7. Joo G, Sohng KY. Accuracy, precision, and validity of fever detection using non-invasive temperature measurement in adult coronary care unit patients with pulmonary catheters. Journal of Korean Academy of Nursing. 2012;42(3):424-433.

https://doi.org/10.4040/jkan.2012.42.3.424

8. Opersteny E, Anderson H, Bates J, Davenport K, Husby J, Myking $\mathrm{K}$, et al. Precision, sensitivity and patient preference of non-invasive thermometers in a pediatric surgical acute care setting. Journal of Pediatric Nursing. 2017;35:36-41. https://doi.org/10.1016/j.pedn.2017.02.003

9. Yun GW, Lim IS. A study for accuracy and usefulness of tympanic membrane and forehead thermometers. Korean Journal of Pediatrics. 2005;48(8):820-825.

10. Park EM. Non-contact infrared thermometer in evaluating temperature of critically ill adults [master's thesis]. Daejeon: Eulji University; 2015. p. 1-56.

11. Ryan-Wenger NA, Sims MA, Patton RA, Williamson J. Selection of the most accurate thermometer devices for clinical practice: part 1: meta-analysis of the accuracy of non-core thermometer devices compared to core body temperature. Pediatric Nursing. 2018;44 (3):116-133.

12. Niven DJ, Gaudet JE, Laupland KB, Mrklas KJ, Roberts DJ, Stelfox HT. Accuracy of peripheral thermometers for estimating temperature: a systematic review and meta-analysis. Annals of Internal Medicine. 2015;163(10):768-777. https://doi.org/10.7326/M15-1150

13. McKenzie NE. Evaluation of a new, wearable, precision phasechange thermometer in neonates. Pediatric Nursing. 2003;29(2): 117-125.

14. Dambrosio N, Porter M, De Lima M, Bauer E, Liedtke D, Levitan N, et al. Continuous temperature monitoring for earlier fever detection in neutropenic patients: patient's acceptance and comparison with standard of care. Biology of Blood and Marrow Transplantation. 2018;24(3):S108-S109.

https://doi.org/10.1016/j.bbmt.2017.12.026

15. Siedlecki S, Butler R. 1276: Accuracy and precision of noninvasive temperature monitoring device compared to PAC in adults in ICU. Critical Care Medicine. 2018;46(1):621. https://doi.org/10.1097/01.ccm.0000529279.42781.51

16. American Society for Testing and Materials. E1112-00 Standard specification for electronic thermometer for intermittent determination of patient temperature. West Conshohocken, PA: ASTM International; 2006. p. 1-4.

17. Yoo JH, Cho HS. Comparison of tympanic and axillary temperatures. 
Journal of Fundamentals Nursing. 2009;16(2):162-170.

18. Oguz F, Yildiz I, Varkal MA, Hizli Z, Toprak S, Kaymakci K, et al. Axillary and tympanic temperature measurement in children and normal values for ages. Pediatric Emergency Care. 2018;34(3):169-173. https://doi.org/10.1097/PEC.0000000000000693

19. Jahanpour F, Azodi P, Zare N. A comparative study on temperature accuracy between tympanic, rectal, and axillary sites. Iranian Journal of Medical Sciences. 2008;33(1):49-53.

20. Park YJ, Park SH, Kang CB. Systematic review and meta-analyses of diagnostic accuracy of infrared thermometer when identifying fever in children. Journal of Korean Academy of Nursing. 2013;43 (6):746-759. http://doi.org/10.4040/jkan.2013.43.6.746

21. Westin E, Levander MS. Parent's experiences of their children suffering febrile seizures. Journal of Pediatric Nursing. 2018;38:68-73. https://doi.org/10.1016/j.pedn.2017.11.001

22. Rofiqo S, Isyti'aroh I. Effort to reduce anxiety levels among mothers using febrile convulsions educational package. Belitung Nurs- ing Journal. 2018;4(4):390-396.

https://doi.org/10.33546/bnj.386

23. Walsh A, Edwards H, Fraser J. Attitudes and subjective norms: determinants of parents' intentions to reduce childhood fever with medications. Health Education Research. 2008;24(3):531-545. https://doi.org/10.1093/her/cyn055

24. Kelsey J, McEwing G. Clinical skills in child health practice. London: Churchill Livingstone; 2008. p. 87-92.

25. Kumar P, Lee HJ. Security issues in healthcare applications using wireless medical sensor networks: a survey. Sensors. 2012;12(1): 55-91. https://doi.org/10.3390/s120100055

26. Comstock J. Kinsa's crowdsourced smart thermometer data now rivals the $\mathrm{CDC}$ at tracking flu trends [Internet]. Cambridge, MA: Mobi Health News; 2018 [cited 2019 January 17]. Available from: https://www.mobihealthnews.com/content/kinsas-crowdsourc ed-smart-thermometer-data-now-rivals-cdc-tracking-flu-trends 